\title{
Revista Brasileira de Enfermagem REBEn \\ A prática de cuidar do ser enfermeiro sob o olhar da equipe de saúde
}

\author{
Nurse's care practice according to the view of the healthcare team \\ La práctica de atención de lo enfermero según la vision del equipo de salud
}

\section{Maria de Loudes Castanha}

Enfermeira. Diretora de Enfermagem do Hospital Pequeno Príncipe de Curitiba/PR e membro do Núcleo de Estudos, Pesquisa e Extensão em Cuidado Humano de Enfermagem (NEPECHE)

UFPR).

castanha@hpp.org.br

Ivete Palmira Sanson Zagonel

Enfermeira. Professora Sênior do Programa de Pós-Graduação em Enfermagem da UFPR, Coordenadora do NEPECHE/UFPR, Coordenadora do Curso de Enfermagem do IESPP. Orientadora da dissertação. ivetesanzag@yahoo.com.br

Trabalho resultante da dissertação do Mestrado em Enfermagem da UFPR.

\section{RESUMO}

Estudo que objetiva compreender a percepção da equipe de saúde sobre a (in)visibilidade da prática de cuidar do ser enfermeiro em unidades críticas pediátricas, à luz da Teoria Humanista de Paterson e Zderad. Trata-se de pesquisa qualitativa, fenomenológica, que utiliza a entrevista semi-estruturada para coleta dos depoimentos e se desenvolveu nas unidades críticas pediátricas de um hospital de Curitiba. Os sujeitos foram enfermeiros, médicos, psicólogos, fisioterapeutas, técnicos e auxiliares de enfermagem e auxiliares de higienização. Da análise, que seguiu os passos propostos por Giorgi, emergiram seis categorias, sendo três relacionadas ao enfermeiro e três à equipe multiprofissional. Com base nos relatos, delineia um modelo conceitual sobre a percepção da (in)visibilidade da prática de cuidar e aponta caminhos para a visibilidade do ser enfermeiro. Descritores: Cuidados de enfermagem; Enfermagem; Equipe de assistência ao paciente.

\section{ABSTRACT}

This study aims to comprehend the healthcare team perception about the (in)visibility of care practice of being a nurse in pediatric critical care units, according to Paterson and Zderad Humanist Theory. This is a qualitative research that combines the phenomenological approach. For data collection, it was used semi-structured interviews with nurses, physicians, psichologists, physiotherapists, nurse aides and hygienization employes working in pediatric critical care units of a hospital in Curitiba. The analysis followed the steps proposed by Giorgi and presented six categories, being three related to nurses' perception and three related to the multiprofessional team. Based on these statements it was possible to outline a conceptual model of nurses' perception about invisibility in their care practice, and also showed ways to obtain nurses' visibility.

Descriptors: Nursing care; Nursing; Patient care team.

\section{RESUMEN}

Este estudio tiene como objetivo comprender la percepción del equipo de salud a la invisibilidad de la practica del cuidar de lo ser enfermero en unidad critica pediátrico a la luz de la Teoría Humanista de Paterson y Zderad. Investigación cualitativo fenomenológica. Fue utilizado la entrevista semi-estructurada para la compilación de las deposiciones. Fue desarrollado en un hospital infantil de Curitiba. Las personas envolvidas fueron enfermeros, doctores, psicólogos, fisioterapeutas, técnico/auxiliar de enfermagen y auxiliar de higienización. Para el análisis se han seguido los pasos propuestos por Giorgi. De lo que fue captado, surgieron seis categorías, tres de ellas relacionada con el enfermero y otras tres a el equipo multiprofesional. Con base en los datos obtenidos fue trazado un modelo conceptual que expone la percepción de la (in) visibilidad de la practica del cuidado, señalando también caminos para la visibilidad del ser enfermero.

Descriptores: Atención de enfermería; Enfermería; Grupo de atención al paciente.

Castanha ML, Zagonel IPS. A prática de cuidar do ser enfermeiro sob o olhar da equipe de saúde. Rev Bras Enferm 2005 set-out; 58(5):556-62.

\section{INTRODUÇÃO}

Partindo dos resultados da pesquisa sobre a (in)visibilidade da prática de cuidar do ser enfermeiro sob o olhar da equipe de saúde ${ }^{(1)}$, em que se buscou desvelar a visibilidade ou invisibilidade do trabalho do enfermeiro, ao desenvolver suas práticas cuidativas, percebe-se que o enfermeiro, assim como qualquer outro profissional da equipe de saúde, procura, por meio de suas atividades, reconhecimento e a conseqüente visibilização, tanto dentro da equipe quanto aos olhos daqueles para os quais presta seus serviços profissionais. Para tanto, torna-se importante que, ao desempenhar tais práticas de cuidado, ele mostre conhecimento e competência técnica, associados à relação intersubjetiva e dialógica desenvolvida com a equipe, com os clientes, a família e a instituição. Essa última, nos tempos atuais, atribui ao enfermeiro o papel de seu representante junto ao cliente, aquele que recebe seus cuidados. 
O cuidado voltado às diferentes dimensões humanas é uma ação que possibilita a visibilidade do enfermeiro, assim como abre espaço para a manutenção da visibilidade da prática de cuidar. A conquista da visibilidade passa primeiramente pela própria pessoa, para depois atingir o coletivo. O ser enfermeiro necessita ter esse convencimento de que é visível, para, então, ser visível perante os outros profissionais. Há três estados básicos da consciência humana, que podem ser aplicados à visibilidade ou não do processo de cuidar dos enfermeiros: o estado aparente, 0 estado escondido e 0 estado intermediário(2). Ao se fazer uma analogia com as práticas da enfermagem, tem-se o saber e o fazer em enfermagem inseridos nessas três possibilidades: 0 cuidado aparente, evidenciado pela racionalidade, intelectualidade e objetividade; o cuidado escondido, demonstrado pela intuição, criatividade e subjetividade; e o cuidado intermediário, que contém algo dos dois primeiros e manifesta-se na sincronicidade, na essência, no movimento e na espontaneidade.

Constata-se, no dia-a-dia, que o cuidar em enfermagem liga-se à comunicação existente entre os próprios enfermeiros, entre enfermeiro, cliente e família e entre enfermeiro, equipe e ambiente. Nesse sentido, Paterson e $\mathrm{Zderad}^{\left({ }^{(3)}\right.}$ ao delinearem a teoria humanista, enfatizam que o profissional enfermeiro mantém com o outro não uma simples relação sujeito-objeto, tecnicamente competente, mas sim uma relação intersubjetiva, baseada na consciência existencial que ele tem de si e do outro. Ainda, o espaço onde se encontra o doente é um local de transações intersubjetivas, em que o enfermeiro mantém constante interdependência com o cliente, a família e a equipe, e eles com 0 enfermeiro. Assim, tal contexto é propício para firmar relações e conquistar a visibilidade ${ }^{(3)}$.

A escolha da teoria de Paterson e Zderad( ${ }^{(3)}$ para sustentar 0 referencial teórico deste estudo fundamenta-se na aproximação de suas idéias e proposições com os objetivos que busco atingir, pois elas oferecem subsídios que demonstram a verdadeira articulação entre todos os envolvidos no processo de cuidar. Já a inquietação consiste em descobrir como os membros da equipe percebem o cuidado do ser enfermeiro, uma vez que a prática aponta que, por meio da atuação profissional, surge a visibilidade.

A necessidade de reconhecimento dos enfermeiros como membros importantes da equipe de saúde, especialmente quanto aos aspectos de cuidar, remete a pensar sobre a valorização que se atribui aos pares e aos outros membros da equipe. Na trajetória da prática, dar visibilidade à profissão é também buscar parcerias, compartilhar responsabilidades e tarefas ${ }^{(4)}$.

Ao discorrer a visibilidade que perpassa a prática, enfatiza-se que a prática dá visibilidade e resume o significado de uma profissão no espaço social, porque, nela, consubstancia-se a realização do compromisso social, que, sendo obrigatório e coletivo, assegura à profissão sua continuidade no tempo e no espaço(5). Tal pensamento complementase com a afirmação de que a prática determina a posição do enfermeiro na sociedade, assegurando ganhos simbólicos que lhe permitem manter sua autonomia (individual e coletiva) no mesmo local(5).

Nessa perspectiva, existem duas intenções distintas e simultâneas, ao enfermeiro que procura ser elemento de referência: viabilizar a assistência e impor-se profissionalmente, criando oportunidades para abrir espaço nessa direção( ${ }^{(6)}$. Ainda, o fazer do enfermeiro tem por motivação maior a sua identidade, que é ser visto, reconhecido, procurado e aceito como o 'profissional enfermeiro', que se dá no cotidiano da relação com os significantes e clientes, outros enfermeiros e o médico.

Nessa mesma linha, entende-se que 0 cuidado não pode se dar isoladamente, pois se trata de uma ação e de um processo interativo, que ocorre entre o ser que cuida e aquele que é cuidado, e se desenvolve por meio da disponibilidade, confiança, receptividade e aceitação, promovendo o crescimento de ambos ${ }^{(7)}$.

No processo de cuidar, é importante que o enfermeiro se coloque em sintonia com os pais e familiares da criança ou do adolescente, pois tal interação tem a finalidade de oferecer o melhor na relação cuidativa, uma vez que, geralmente, durante o percurso da doença, as crianças e os adolescentes, assim como suas famílias, estão sensibilizados e sentem-se desamparados, os pais, especialmente, quando não conhecem o processo de tratamento e a evolução da doença que acomete seu filho.

Assim, cabe ao enfermeiro, como elemento mobilizador das ações de cuidado, utilizar, com o doente e com sua família, uma forma de comunicação descrita como sendo a mais clara e simples possível(8). Tal forma de comunicação, aliada à capacidade e à sensibilidade demonstrada pelo enfermeiro e pela equipe de saúde, é, por vezes, mais valorizada pelo cliente do que a falta de acomodação e até de medicamentos.

A questão da visibilidade profissional, especialmente em unidades críticas pediátricas (UCP), local de realização desta pesquisa, alia-se ao desempenho rápido e preciso, à capacidade de diálogo empático com o cliente e demais membros da equipe, a fim de propiciar um ambiente agradável, respeitoso e acolhedor para todos os envolvidos. Em tal ambiente, o enfermeiro torna-se uma espécie de 'diálogo humano', porque está em constante transação intersubjetiva, com todos os participantes de seu mundo de trabalho(3). O momento do cuidado tornase, então, segundo a teoria humanista, um tempo privilegiado, no qual o enfermeiro pode 'doar-se' para o cliente, ao mesmo tempo em que 'recebe' algo dele, num pacto mudo de comunicação intersubjetiva profunda.

\section{METODOLOGIA}

Para desenvolver este trabalho, optou-se pela pesquisa fenomenológica, à luz do referencial teórico de Paterson e Zderad ${ }^{(3)}$. Utilizou-se, para a coleta das informações, a entrevista fenomenológica semi-estruturada e, para a compreensão dos discursos, os passos de análise propostos por Giorgi(9).

A escolha pela pesquisa fenomenológica deu-se por ela ser uma metodologia congruente com a teoria humanista( ${ }^{(3)}$, pois possibilita ao enfermeiro conhecer o outro por reflexão, desvelamento e compreensão, ou seja, ver o outro pelos olhos do sujeito interrogado, detectando as similaridades e diferenças da vivência do diálogo no cuidado.

A literatura descreve a fenomenologia como um movimento cujo objetivo precípuo é a investigação direta e a descrição de fenômenos que são experienciados conscientemente, sem teorias sobre a sua explicação causal e tão livre quanto possível de pressupostos e preconceitos $^{(10)}$. Esse pensamento é compartilhado por outro autor ${ }^{(11)}$, ao escrever que a fenomenologia propõe a investigação de o que é vivido, descrevendo os fenômenos como eles são sentidos, despojados de todo tipo de conceitos e teorias a seu respeito, permitindo, portanto, interpretação e compreensão mais verdadeiras do fenômeno.

O contexto de realização deste trabalho incluiu quatro Unidades Críticas Pediátricas de um hospital pediátrico de grande porte de Curitiba, considerado de referência no tratamento de crianças e adolescentes de zero a 18 anos, em todas as especialidades.

Como sujeitos da pesquisa, optou-se pela equipe de saúde, entendida, neste trabalho, como aqueles que atuam diretamente no cuidado nas unidades críticas pediátricas, neste caso: 7 enfermeiros, 4 médicos, 2 fisioterapeutas, 2 psicólogos, 2 técnicos e auxiliares de enfermagem e 2 auxiliares de higienização, totalizando 19 sujeitos. A decisão pelas Unidades Críticas Pediátricas deu-se porque, ali, há maior solicitação do profissional enfermeiro, estando ele em evidência por meio de sua autonomia, competência, qualidades, defeitos, formas de relacionamento e efetivação do cuidado complexo. Os sujeitos foram 
divididos em dois grupos, sendo um composto por 7 enfermeiros e outro composto por 12 profissionais de saúde, de modo que se utilizaram, portanto, dois instrumentos distintos para a coleta dos depoimentos.

Para os enfermeiros, foram utilizadas as seguintes questões de pesquisa:

1. Como você se percebe como enfermeiro, desenvolvendo as ações de cuidado em UCP?

2. Quais os aspectos que indicam que o seu trabalho é (in)visível?

3. A sua prática tem repercussão no agir dos demais profissionais da equipe em UCP?

Para os demais profissionais, as questões foram:

1. Em sua convivência diária com os enfermeiros na unidade crítica pediátrica, o que você vê e observa, frente às ações de cuidado que eles desempenham?

2. Você acha que o trabalho deles é (in)visível?

3. O modo de agir do enfermeiro tem repercussão no seu agir profissional?

Quanto aos aspectos éticos, solicitou-se a colaboração espontânea de cada sujeito, mediante contato pessoal, visando a esclarecer os motivos da pesquisa e conhecer a disponibilidade de cada um. Para aqueles que aceitaram participar, foram agendados dia, hora e local para realização da entrevista. Foi, ainda, solicitado autorização institucional ao Comitê de Ética do Hospital em estudo. Somente após a obtenção do aceite, iniciaram-se os contatos.

Todos os participantes receberam os termos de consentimento livre e esclarecido, que, depois de lidos e comentados, foram assinados, permitindo-se inclusive a gravação das entrevistas para posterior transcrição. O zelo ético permeou todo o processo de investigação, considerando-se o que preconiza a Resolução 196/96 do Conselho Nacional de Saúde, que trata de pesquisa com seres humanos.

\section{RESULTADOS E ANÁLISE}

A análise dos depoimentos coletados representa um momento analítico no processamento da informação e torna-se parte da qualidade da informação produzida pela pesquisa. Nesse mesmo pensamento, a análise é uma forma de penetrar nas estruturas simbólicas que configuram a vida cotidiana das pessoas em seus contextos reais ${ }^{(12)}$.

Neste trabalho, após a transcrição das entrevistas, utilizou-se 0 caminho de análise proposto por Giorgi(9) 0 qual estabelece os passos essenciais do método fenomenológico:

PASSO 1: O pesquisador lê as descrições, a fim de obter o sentido geral do todo;

PASSO 2: O pesquisador lê novamente o texto e transforma-o em linguagem da ciência, com o objetivo específico de discriminar as Unidades de Significado, com foco no fenômeno que está sendo pesquisado, conforme mostra o Quadro 1.

PASSO 3: O pesquisador expressa os insights contidos no todo das unidades de significação, que revelam o fenômeno sob consideração.

Ao efetivar-se o Passo 3, desvelaram-se dos discursos dez Unidades de Significação (US), que foram analisadas a partir das expressões de cada enfermeiro, ou seja, essas US foram encontradas em cada discurso. Somente após conclusão da análise de cada discurso iniciouse a análise global, reunindo-se, então, todos os discursos, ou seja, as partes que compunham o todo, como se observa no próximo passo de análise.

Unidades de significação captadas das descrições dos sujeitos enfermeiros

1) Compreendendo os atributos pessoais como padrão fundamental para 0 cuidado;

2) Compreendendo-se como pessoa que pode ir além;

3) Compreendendo o cuidado humano como dimensão que diferencia 0 trabalho do enfermeiro e lhe outorga a visibilidade;

4) Compreendendo a dimensão técnica no desempenho profissional;

5) Compreendendo a inter-relação entre saber científico e responsabilidades como forma de suplantar a subalternidade;

6) Compreendendo a temporalidade do ser enfermeiro no desempenho profissional do cuidado;

7) Compreendendo o diálogo vivido na relação do ser enfermeiro com a equipe de saúde;

8) Compreendendo o reconhecimento do trabalho do enfermeiro pelos demais profissionais de saúde e família;

9) Compreendendo a relação do enfermeiro com a instituição;

10) Compreendendo o humanismo profissional do enfermeiro como aspecto de repercussão sobre os demais membros da equipe, família e do paciente.

PASSO 4: O pesquisador reflete e sintetiza todas as unidades de significado, transformadas em afirmações consistentes a respeito da experiência do sujeito (categorias convergentes).

O Passo 4 reúne todas as informações obtidas dos 7 enfermeiros entrevistados, abstraindo-se, então, as categorias convergentes, conforme mostra o Quadro 2. É importante salientar que as US que estão na coluna da direita foram extraídas dos discursos. Nada foi inferido, complementado ou acrescentado pelo pesquisador. Nessa fase, o conhecimento e a experiência do pesquisador contam muito, pois é a partir desse referencial que ele consegue apreender as US articuladas às categorias convergentes.

O mesmo processo de análise efetivou-se para os discursos da equipe de saúde, obtendo-se o Quadro 3, a seguir.

\begin{tabular}{|l|l|}
\hline Síntese das categorias identificadas do discurso do sujeito & $\begin{array}{l}\text { Ordenação da transcrição das unidades de significado numeradas da linguagem ingênua } \\
\text { para a linguagem da pesquisadora }\end{array}$ \\
\hline $\begin{array}{l}\text { Discurso 1 } \\
\text { 1. Como você se percebe como enfermeiro desenvolvendo as ações de } \\
\text { cuidado em UCP? }\end{array}$ & \\
\hline $\begin{array}{l}\text { Na minha unidade, eu vejo que tecnicamente os enfermeiros se equiparam (1). A } \\
\text { diferença eu acho que é maior no atendimento humano, no cuidado direto com o } \\
\text { paciente, no tratar (2), e isso se percebe também que é uma diferença de } \\
\text { personalidade não só de aprendizado técnico (3), mas é o psicológico, talvez a } \\
\text { criação do enfermeiro que faz essa diferença (4). Na equipe, dentre os os }\end{array}$ & (2) Expressa as diferenças no trabalho do enfermeiro com enfoque na dimensão humana. \\
enfermeiros, dentre todos os enfermeiros que nós somos, a gente vê a diferença, \\
$\begin{array}{l}\text { não só com relação ao restante da equipe (5). Talvez, a equipe técnica, que está } \\
\text { mais junto com o paciente, tenha atitudes mais humanizadas do que o próprio enfermeiro como diferenciado pela personalidade do profissional. } \\
\text { enfermeiro (6). }\end{array}$ & $\begin{array}{l}\text { (4) Atribui a diferença ao psicológico, à forma de criação do enfermeiro. } \\
\text { (5) Admite ser diferente o trabalho do enfermeiro perante a equipe. }\end{array}$ \\
\hline
\end{tabular}

Quadro 1. Exemplo das categorias do discurso do sujeito e da transcrição das unidades de significado. 


\begin{tabular}{|l|l|}
\hline Categorias convergentes na compreensão da pesquisadora & Unidades de significação das descrições dos sujeitos enfermeiros \\
\hline O self do ser enfermeiro articulado ao vir-a-ser profissional & $\begin{array}{l}\text { 1) Compreendendo os atributos pessoais como padrão fundamental para o cuidado; } \\
\text { 2) Compreendendo-se como pessoa que pode ir além; }\end{array}$ \\
\hline $\begin{array}{l}\text { O ser enfermeiro na convivência coletiva com os demais } \\
\text { profissionais de saúde, a família } \\
\text { e a instituição }\end{array}$ & $\begin{array}{l}\text { 7) Compreendendo o diálogo vivido na relação do ser enfermeiro com a equipe de saúde; } \\
\text { 8) Compreendendo o reconhecimento do trabalho do enfermeiro pelos demais profissionais de saúde e família; } \\
\text { 9) Compreendendo a relação do enfermeiro com a instituição; }\end{array}$ \\
$\begin{array}{l}\text { O ser enfermeiro profissional diante da (in)visibilidade da } \\
\text { prática do cuidado }\end{array}$ & $\begin{array}{l}\text { 10) Compreendendo o humanismo profissional do enfermeiro como aspecto de repercussão sobre os demais o cuidado humano como dimensão que diferencia o trabalho do enfermeiro e lhe outorga a } \\
\text { visibilidade; }\end{array}$ \\
& $\begin{array}{l}\text { 4) Compreendendo a dimensão técnica no desempenho profissional; } \\
\text { 5) Compreendendo a inter-relação entre o saber científico e responsabilidades como forma de suplantar a } \\
\text { subalternidade; }\end{array}$ \\
\hline
\end{tabular}

Quadro 2. Categorias convergentes e unidades de significado dos Enfermeiros.

\begin{tabular}{|l|l|}
\hline Categorias convergentes na compreensão da pesquisadora & Unidades de significação das descrições dos sujeitos \\
\hline $\begin{array}{l}\text { A. A convivência da equipe de saúde no cotidiano de cuidado } \\
\text { do enfermeiro }\end{array}$ & $\begin{array}{l}\text { 1. Compreendendo a amplitude das ações de cuidado que o enfermeiro executa. } \\
\text { 2. Compreendendo a dialogicidade como fundamento para as relações de humanidade entre enfermeiro e equipe. } \\
\text { 3. Compreendendo o cotidiano do cuidado do enfermeiro como instrumento de aprimoramento da equipe de } \\
\text { enfermagem. }\end{array}$ \\
\hline $\begin{array}{l}\text { B. A visão da equipe de saúde sobre a (in)visibilidade do } \\
\text { enfermeiro }\end{array}$ & $\begin{array}{l}\text { 4. Compreendendo as dimensões de experiência, segurança e conhecimento como fatores de visibilidade do } \\
\text { enfermeiro. }\end{array}$ \\
$\begin{array}{l}\text { 5. Compreendendo a presença do enfermeiro na unidade, como fator influenciador da visibilidade. } \\
\text { 6. Compreendendo a importância da habilidade técnica no cuidado. }\end{array}$ \\
$\begin{array}{l}\text { 7. Compreendendo a interação do enfermeiro com o cliente e a família. } \\
\text { C. A repercussão do agir profissional do enfermeiro no agir } \\
\text { profissional da equipe de saúde }\end{array}$ \\
$\begin{array}{l}\text { 8. Compreendendo o ser enfermeiro como indispensável na realização das ações de cuidado em UCP. } \\
\text { 9. Compreendendo a expressão da equipe de saúde sobre os aspectos contribuintes da invisibilidade. } \\
\text { 10. Compreendendo a humanização e o compromisso do enfermeiro como tendo ressonância na equipe. }\end{array}$ \\
\hline
\end{tabular}

Quadro 3. Categorias convergentes e unidades de significado da Equipe.

\section{COMPREENSÃO DA (IN)VISIBILIDADE DA PRÁTICA DE CUIDAR}

Dos discursos, emergiu que a visibilidade, assim como a invisibilidade do enfermeiro, nas ações de cuidado, relaciona-se com a maneira de ser e de estar-com aquilo que o próprio enfermeiro vivencia e expressa por meio de seu ser profissional e da compreensão a seu respeito pelos outros membros da equipe. Os discursos são identificados pelo número de ordem em que foram realizados, ou seja, os discursos de 1 a 7 correspondem aos depoimentos dos enfermeiros e os de 8 a 19 correspondem aos profissionais da equipe de saúde. Uma faceta da visibilidade que se delineia nos discursos da equipe de saúde reflete a postura do profissional enfermeiro frente à evolução da criança, ao longo do processo terapêutico, a qual é enfatizada quando o enfermeiro é participativo, crítico e não-apático.

Aquele enfermeiro que não pergunta nada, não questiona sobre a droga que foi mudada, porque esse paciente estava assim, agora está de outro jeito, é apático. Ele não nos chama a atenção. (D10)

O fenômeno da visibilidade profissional aparece como emergente das manifestações de conhecimento técnico-científico, por parte do ser enfermeiro, da co-participação na tomada das decisões referentes ao cliente ou ao gerenciamento da unidade e na forma humanizada de cuidar.

Eu penso também que os enfermeiros precisam estudar mais, se graduar mais, aprender mais para também ter uma postura diferente, com relação aos funcionários, também saber colocar a sua posição como enfermeiros. Também saber colocar o seu lado humano,se igualar a eles, no momento, você é uma pessoa como todas as outras ali dentro da unidade.(D1)

Aquele enfermeiro que detecta precocemente as alterações e comunica o médico ajuda para que a criança possa recuperar-se mais rapidamente ou não sofrer as conseqüências de uma conduta demorada, que pode causar mais danos do que os já existentes, é por nós visibilizado. (D11)

O cuidado que o enfermeiro é chamado a ofertar cotidianamente significa desvelo, solicitude, diligência, zelo, atenção bom trato, de modo que é a atitude fundamental, mediante a qual a pessoa sai de si e centra- se no outro com desvelo e solicitude ${ }^{(12)}$. No discurso, evidencia-se a importância de deixar que o lado humano do enfermeiro desabroche na prática.

Pode ser um ótimo enfermeiro ou outro profissional, mas, se não tiver o mínimo de escuta, não terá muito valor para a manutenção da relação. (D15)

O enfermeiro é muito mais sensível do que o médico, para os desejos do cliente. O lado humano é mais visível neles. (D14)

Atributos como iniciativa, experiência e segurança que ele transmite à equipe foram apontados como fatores de visibilidade. Profissionais que se reciclam constantemente ou estudam os casos novos que aparecem no seu ambiente de trabalho são ativos, observadores, comunicativos, questionadores, detalhistas, atuantes, 'põem a mão na massa', sabem se posicionar, mantendo boas relações e criando vínculos positivos, além de conseguir detectar precocemente possíveis complicações nos clientes, são reconhecidos e visibilizados pela equipe.

Quando eu falo de estudar mais, pode não ser apenas fazer uma pós, mas pode ser também a leitura pura e simples daquilo que ele esta fazendo no momento, fazendo no dia a dia, porque a gente não vê, é muito difícil você ver um enfermeiro estudando aquilo que ele está fazendo. Ele vai fazendo, vai fazendo e acha que não precisa mais. $E$ na verdade a gente sabe que quanto mais você ler, mais se aprimora, mais tem capacidade para discutir o assunto, para se colocar e para fazer. (D1)

Eu acho que é visível e que qualquer pessoa da equipe pode identificar o trabalho deles, porque o próprio enfermeiro demonstra isso, quando mostra segurança ou insegurança naquilo que faz. (D9)

Eu acho que o conhecimento, a experiência e a segurança que ele passa são fatores que ajudam o enfermeiro a ser mais bem visto dentro da equipe. (D9)

O enfermeiro é uma segurança, porque seu trabalho não se compara ao nível técnico. Mesmo o nível das informações que são passadas tem outra qualidade. (D10)

O discurso revela que as capacidades humanas de compreender, 
saber ouvir, relacionar-se, ter responsabilidade, saber dialogar, ter atitudes humanizadas tornam o ser enfermeiro capaz de fazer, com sua presença, a diferença na equipe.

Aqueles que têm habilidades, responsabilidades, são questionadores, ajudam, estão por perto, fazem sugestões são visíveis. (D12)

Eu acho que trabalhar com humanização, fazer um trabalho de qualidade e buscar constantemente o conhecimento, o saber, a atualização das técnicas e tecnologias leva, sem sombra de dúvida, à visibilização do enfermeiro, porque ele está sempre buscando crescimento, melhoria, para servir melhor. (D17)

Eu também acho que a pessoa competente no seu trabalho nem precisa fazer muito barulho para aparecer. As conseqüências dele vão acabar aparecendo. (D15)

Esses fragmentos do discurso apontam que o enfermeiro que não apenas manda, mas faz junto, ensina, orienta, torna-se referência para a equipe. Na cotidianidade, entende-se que uma das faces da articulação que deve existir na equipe é a cooperação no trabalho, entendida como 'fazer junto', especialmente aqueles procedimentos técnicos que possam ser melhor desempenhados com ajuda ${ }^{(14)}$.

Pessoas ativas, observadoras e atuantes que ajudem a prevenir complicações dentro da unidade, isto é, profissionais que atuem na prevenção, pessoas que chequem pessoas, aparelhos, alarmes, para que tudo esteja funcionando. (D12)

O movimento da invisibilidade para a visibilidade, a mudança de um status para outro, exige articulação e sintonia, além de se considerar que o ser enfermeiro é o centro de todo esse processo. O ser enfermeiro está articulado ao ser pessoal, que é o seu próprio self, ao ser profissional, que presta os cuidados ao cliente e à família, e ao ser coletivo, isto é, que interage com a equipe com a qual convive.

Existe, portanto, uma intercessão, uma interface entre todas essas características, que não podem ser dissociadas da prática profissional. O ser enfermeiro congrega a articulação destas três dimensões: pessoal, profissional e coletiva. A partir do momento em que essa articulação entra em movimento, várias atribuições, funções e aspectos compõem esse processo de trabalho, para auxiliar a visibilidade do ser enfermeiro. Dentre esses aspectos, é possível citar a atualização e 0 desenvolvimento pessoal, profissional e coletivo. A interação com o outro ajuda a transformar o próprio modo de ser, fazer e conviver, melhorando, assim, as alianças com a equipe. A responsabilidade, o engajamento, a gentileza, empatia, o respeito, interesse e amor são sentimentos que necessitam estar interligados, para que esse processo de trabalho que envolve o processo de cuidar do ser enfermeiro torne-se visível.

Todos devem primar pelo técnico, sem perder o lado humano dos relacionamentos e a capacidade de ver cada doente como único. (D15)

Precisamos de profissionais sensibilizados para esse tipo de necessidades, que mantenham um bom padrão de atendimento, para que possamos dar mais conforto ao nosso usuário. (D12)

A visibilidade é pessoal, profissional e coletiva, porque envolve 0 ser do enfermeiro como pessoa, o ser enfermeiro profissional e o ser de relações do enfermeiro com a equipe de saúde, que é o coletivo.

Esse trabalho de bastidores deles acaba aparecendo na rapidez com que muitas coisas são resolvidas. (D12)
* Articulaçáo do fazer

tóćnico aos atributos de humanizaçāo

* Competencia

${ }^{*}$ Eficiénciz e rapidez

* Resolubilidade

* Diálogo intersubjetivo

* Comunicaçto

* Qualidade das açoes

*Administraçấo do tempo

* Antecipaça do cuidado

* Planejarnento e organizaŗão

* Responsabilidade ética

* Necessidade de

reconhecimento

* Exizéncias financeiras

* Sobrecarga de uabalho

* Escresse do ambiente de

UCP

* Qualificaçäo constante

* Imposiçōes e controles instituciomais

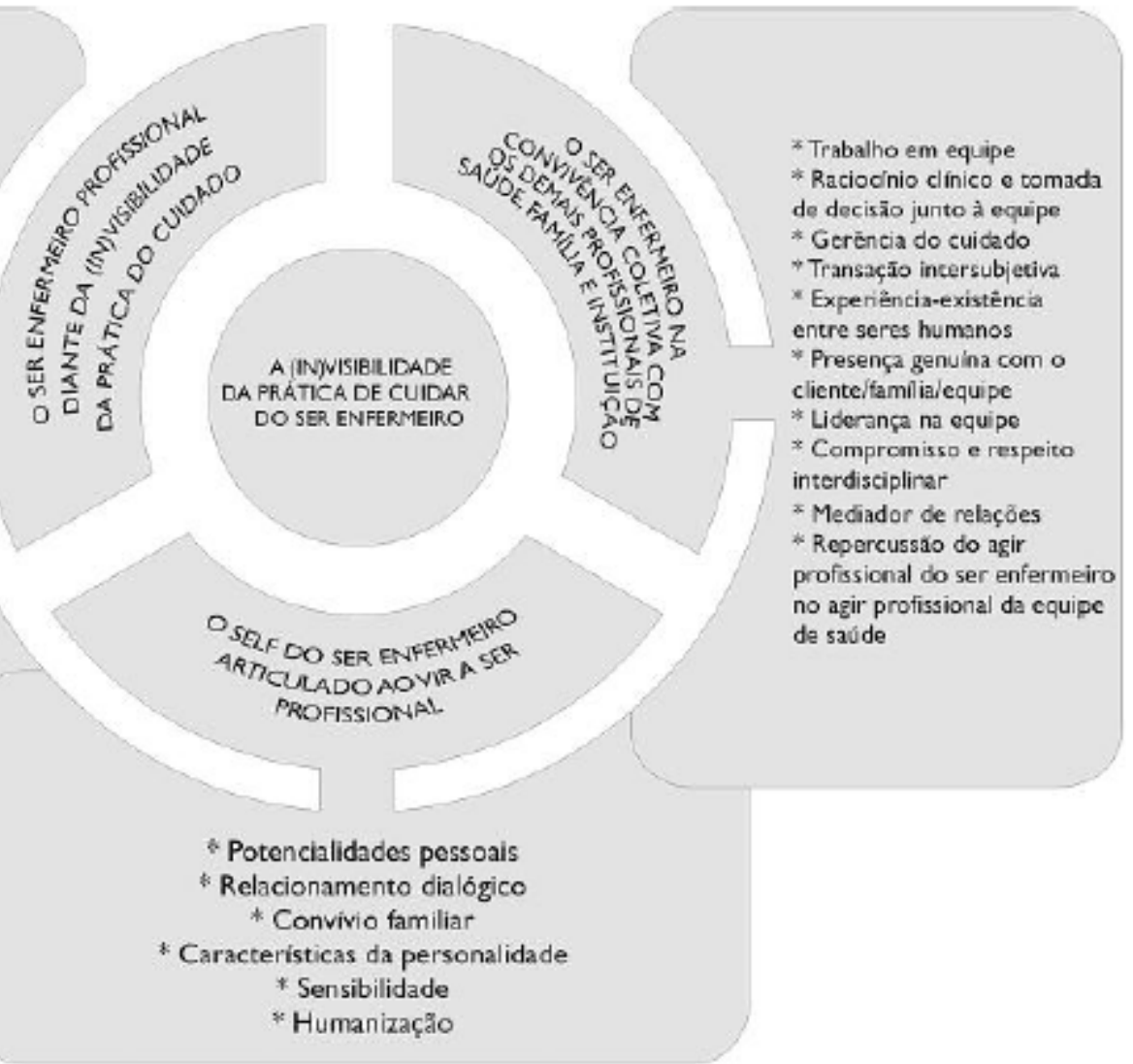

Figura 1. Modelo conceitual da percepção da equipe de saúde sobre a (in)visibilidade da prática do cuidado do ser enfermeiro em Unidades Críticas Pediátricas ${ }^{(1)}$. 
Mas a dedicação dos enfermeiros e sua equipe é algo incontestável. (D13)

Se cada profissional da equipe fizer o que deve bem feito, o resultado aparece, e o paciente ganha em qualidade no cuidado. (D17)

A partir do que se apreendeu, delineou-se o modelo conceitual seguinte, no qual se apresenta a dinâmica que envolve a visibilidade do profissional enfermeiro, tendo-se como centro a prática de cuidar do ser enfermeiro. Interligadas ao foco central estão as três dimensões que compõem o processo de visibilidade buscado neste trabalho. Como primeira dimensão apreendida, tem-se o self do ser enfermeiro relacionado às potencialidades pessoais, ao convívio familiar de sensibilidade, de humanidade, de relacionamentos, necessários à prática de cuidar. A segunda dimensão é o ser enfermeiro profissional, que necessita de conhecimento, planejamento, comunicação, competência, eficiência, rapidez, resolutividade, atualização constante, a fim de dar suporte à terceira dimensão, que é o ser enfermeiro na coletividade, e envolve trabalho em equipe, presença genuína de cliente, família e equipe, mediação de relações, transação intersubjetiva, além das habilidades técnicas. 0 modelo aponta a relação existente entre o ser enfermeiro pessoa, o ser enfermeiro profissional e o ser enfermeiro na convivência coletiva com o cliente, a equipe e instituição. Da presença ou ausência de harmonia nesse movimento em três dimensões depende a visibilidade ou invisibilidade do profissional enfermeiro.

\section{CONSIDERAÇÕES FINAIS}

A escolha do objeto deste estudo, ou seja, a (in)visibilidade da prática de cuidar do ser enfermeiro em Unidades Críticas Pediátricas, partiu do desejo de desvelar tal fenômeno, sob a ótica da equipe de saúde, para melhor compreender, no processo de cuidar e auscultar, por meio dos discursos, como efetivamente o ser enfermeiro é visto pela equipe de saúde. Essa compreensão auxilia no modo de gerenciar o cuidado, em mudanças de postura e comportamentos, em maior atenção no preparo técnico-científico de cada profissional envolvido e, principalmente, em tornar visível o papel do ser enfermeiro na prática de cuidar, sua essência. O significado emergido das falas dos depoentes elucida que o ser enfermeiro, em sua prática de cuidar, tem papel fundamental no ambiente de trabalho, mesmo que, muitas vezes, não exista a consciência desse fato ou o enfermeiro não se sinta detentor desse papel naquela unidade.

No ambiente de trabalho, ele é chamado a ser 'elo', que, por meio de sua conduta humana e profissional, expressa aos demais o quanto valoriza as relações humanizadas entre a equipe e o cliente, sabendo ouvir, sendo disponível, estando e fazendo-com, demonstrando habilidades, conhecimento humano-científico, responsabilidade, assim como senso crítico, observação e boa comunicação.

A partir do conteúdo apreendido dos discursos, é possível conceituar a visibilidade do ser enfermeiro, focando-se o olhar da equipe de saúde.

Visibilidade é reconhecer de forma crítica sua prática, perceber suas

\section{REFERÊNCIAS}

1. Castanha ML. A (in)visibilidade da prática de cuidar do ser enfermeiro sob o olhar da equipe de saúde [dissertação]. Curitiba (PR): Departamento de Enfermagem; Universidade Federal do Paraná; 2004.

2. Santos AM, Rogers CR, Bowen MCVB. Quando fala o coração: essência da psicoterapia centrada na pessoa. Porto Alegre (RS): Artes Médicas; 1987.

3. Paterson JE, Zderad LT. Enfermería humanística. Ciudad de México (MEX): Editorial Limusa S.A.; 1979.

4. Vale EG. A ABEn: a visibilidade da enfermagem e a conquista da emancipação. In: Anais do $53^{\circ}$ Congresso Brasileiro de Enfermagem 2001, Curitiba, Brasil; 2001 Curitiba (PR): ABEn; 2001. p.353-365. lacunas, é, antes de tudo, um processo que deve ser exercitado e notabilizado como eixo norteador para efetivar um cuidado de qualidade pelo enfermeiro;

Visibilidade dá-se pelo rompimento do modo de agir do enfermeiro, voltado apenas ao desempenho técnico, e exige a conjugação de conhecimento, habilidades, experiência, sensibilidade e humanidade no cuidar;

Visibilidade é priorizar, no processo de cuidar do enfermeiro, o estarcom, o olhar, ouvir, tocar, pois esses atributos fazem com que ele utilize o pensamento crítico para a sistematização, organização e reflexão de sua prática e, assim, regule-a no tempo vivido para o cuidar;

Visibilidade legitima o humano das pessoas envolvidas, e isso repercute no ambiente da UCP, reverenciando as pessoas, em vez de 0 aparato tecnológico;

Visibilidade se estabelece no ato de cuidar como evento interhumano, de transação intersubjetiva, dependendo de arranjos entre instrumentos, saberes e relações dos sujeitos envolvidos no encontro do cuidado:

Visibilidade é estar atento a qualquer solicitação do cliente ou da equipe, percebendo os temores, apelos, manifestações, para, então, em uma atitude de solidariedade, realizar a mediação do encontro;

Visibilidade é vislumbrar o fenômeno da verdadeira comunhão, do face a face, da plenitude do encontro, da beleza singular de cada ser, no momento do cuidado.

Visibilidade é cuidar de maneira integral do cliente, agindo na prevenção de complicações, investindo em atualização, tanto para si como para a equipe.

Visibilidade é estabelecer o desafio constante da relação dialógica entre enfermeiro e profissionais da saúde, para, de forma competente, efetivar a convergência da comunicação sensível e a intersubjetividade que permeiam as ações de cuidar;

Visibilidade é agir de forma interdisciplinar e multirrelacional no processo de cuidar, em que a mutualidade, o trabalho compartilhado, a reciprocidade e autenticidade tornam-se elementos básicos;

Visibilidade é comunicação efetiva entre a equipe, o cliente e a família, em que as informações são valorizadas, repassadas e transformadas em ações de cuidado;

Concluindo, considera-se válido enfatizar que este trabalho é perspectival, uma vez que reflete uma compreensão do fenômeno pesquisado, a qual é sempre inacabada e dinâmica. Ele fornece dados importantes sobre a visibilidade e a invisibilidade da prática de cuidar do ser enfermeiro, os quais podem incentivar modificações no relacionamento ser/saber/fazer, assim como facilitar a aproximação entre os sujeitos na equipe e trazer luz sobre o ser enfermeiro, como agente que cuida com responsabilidade, zelo e ética profissionais.

5. Santos TCF. A construção do olhar da enfermagem sobre a sua ação social: na pesquisa, na formação e na história. In: Anais do $53^{\circ}$ Congresso Brasileiro de Enfermagem; 2001, Curitiba, Brasil; 2001. Curitiba (PR): ABEn; 2001. p.61-75.

6. Yoshioca MR. Tendo que ser maior do que os obstáculos para existir como enfermeira [tese]. São Paulo (SP); Escola de Enfermagem; Universidade de São Paulo; 1996.

7. Waldow VR. Cogitando sobre o cuidado humano. Cogitare Enfermagem 1998 jul-dez; 3(2): 7-10.

8. Costenaro RGS. Ambiente terapêutico de cuidado em UTI neonatal: um experimento para a redução do estresse na aspiração oro-traqueal do recém-nascido [tese]. Florianópolis (SC): Universidade Federal de Santa Catarina; 2000 
9. Giorgi A. Phenomenology and psychological research. Pittsburg (USA): Duquesne University Press; 1985.

10. Bicudo MAV. Sobre a fenomenologia. In: Bicudo MAV, Espósito VHC Pesquisa qualitativa em educação. Campinas (SP): Unicamp; 1994. [s.p.].

11. Crossetti MG. Processo de cuidar: uma aproximação existencial na enfermagem [tese]. Florianópolis (SC): Universidade Federal de Santa Catarina; 1997.

12. Rey FLG. Pesquisa qualitativa em psicologia: caminhos e desafios
São Paulo (SP): Pioneira Thomson; 2002.

13. Silva LF, Gurgel AO, Carvalho ZMF, Moreira RVO. Cuidado como essência humana em Martin Heidegger e a enfermagem. In: Moreira RVO, Barreto JAE, organizadores. A outra margem: filosofia, teorias de enfermagem e cuidado humano. Fortaleza (CE): Casa de José de Alencar; 2001. [s.p.].

14. Peduzzi M. Laços, compromissos e contradições existentes nas relações de trabalho de enfermagem. In: Anais do $53^{\circ}$ Congresso Brasileiro de Enfermagem; 2001, Curitiba, Brasil; 2001. Curitiba (PR): ABEn; 2001. [s.p.]. 